\title{
Meconium Induced IL-8 Production and Intratracheal Albumin Alleviated Lung Injury in Newborn Pigs
}

\author{
PAAL H.H. LINDENSKOV, ALBERT CASTELLHEIM, GEIR AAMODT, AND OLA D. SAUGSTAD \\ Department of Pediatric Research [P.H.H.L., A.C., O.D.S.], Department of Biostatistics [G.A.], Institute \\ for Surgical Research [P.H.H.L., A.C.], Rikshospitalet University Hospital, N-0027 Oslo, Norway
}

\begin{abstract}
We have recently shown that albumin added to meconium before intratracheal instillation in newborn pigs limits detrimental effect on the lungs and reduces increase of IL-8. The aim of this study was to test the effect of albumin instillation as rescue treatment in meconium aspiration syndrome (MAS). MAS was induced in hypoxic piglets by lung instillation of meconium $($ MAS I $=675 \mathrm{mg} / \mathrm{kg}, n=12$; MAS II $=540 \mathrm{mg} / \mathrm{kg}, n=14$ ). Morbidity and mortality differed (MAS I, dead $=7 / 12$; MAS II, dead $=5 / 14)$. MAS groups were randomized to postmeconium instillation of either bovine albumin $(30 \%, 1.4 \mathrm{~mL} / \mathrm{kg}$; MAS I, $n=6$; MAS II, $n=7)$ or isotonic saline $(9 \mathrm{mg} / \mathrm{mL}, 1.4 \mathrm{~mL} / \mathrm{kg}$; MAS I, $n=6$; MAS II, $n=7)$. The controls $(n=4)$ were tested by sequential instillation of saline $(9 \mathrm{mg} / \mathrm{mL}, 5 \mathrm{~mL} / \mathrm{kg})$ and albumin $(30 \%, 1.4 \mathrm{~mL} / \mathrm{kg})$. Lung function and gas exchange deteriorated significantly after instillation of meconium [oxygenation index (OI): MAS I, $+814 \%$; MAS II, $+386 \%$; ventilation index (VI): MAS I, +256\%; MAS II, +162\%; compliance: MAS I, $-53 \%$; MAS II, $-44 \%$ ]. Increases of tracheal IL-8 correlated
\end{abstract}

\section{ABSTRACT}

to deterioration of lung function were 10- (MAS I) and 5-fold (MAS II) $(p<0.001)$. Lung compliance was higher in albumin instillation versus saline instillation (MAS I, $p=0.008$; MAS II, $p=0.002$ ). Albumin did not influence intergroup differences in IL-8, hemodynamics, OI, or VI. MAS-induced IL-8 increases correlated with deterioration of lung function (OI, VI, and compliance). Rescue treatment with albumin in meconium aspiration improved lung compliance in piglets and may represent a new therapeutic approach to MAS. (Pediatr Res 57: 371-377, 2005)
LAP, left atrial pressure
Abbreviations
MAS, meconium aspiration syndrome
MAS I, piglets receiving $675 \mathrm{mg}$ meconium $/ \mathrm{kg}$
MAS II, piglets receiving $540 \mathrm{mg}$ meconium $/ \mathrm{kg}$
OI, oxygenation index
PAP, pulmonary artery pressure
VI, ventilation index

Meconium aspiration may cause mechanical obstruction of airways $(1,2)$, inactivate surfactant (3-7), induce pulmonary hypertension $(8,9)$, and trigger inflammation $(8,10,11)$.

Regarding cause of inflammation in MAS, various factors have been proposed. For instance, bile acids $(7,12)$ and FFA (13) in meconium may induce chemical pneumonitis. Endothelial microvascular damage (1) and inflammation (14) have been observed $6 \mathrm{~h}$ after meconium insufflation. Further, an increased neutrophil count and chemotactic activity have been detected in tracheal aspirate $12 \mathrm{~h}$ after instillation of meconium (15).

There is evidence of a favorable effect of glucocorticoids on lung physiologic parameters in MAS (14). Meconium may

Received May 23, 2003; accepted July 6, 2004.

Correspondence: Paal H.H. Lindenskov, M.D., Department of Pediatric Research (PFI), University of Oslo, Rikshospitalet, N-0027 Oslo, Norway; e-mail: p.h.h.lindenskov@klinmed.uio.no

Supported by The Research Council of Norway through a research fellowship for P.H.H.L.

DOI: 10.1203/01.PDR.0000153870.66197.D1 stimulate chemotaxis through its content of IL-8 (16), influence oxidative burst $(17,18)$, and increase activity of phospholipase $A_{2}$ (5), which catalyzes formation of eicosanoids. Finally, meconium may stimulate macrophages to produce tumor necrosis factor (19), nitric oxide (20), and superoxide anion (21).

Meconium contains surfactant inhibitors like FFA $(3,4,22)$, bilirubin (7), and enzymes (5). In vitro, meconium inhibits surfactant even at low concentrations $(6,23)$. Albumin may also inhibit surfactant. The mechanism of surfactant inhibition by albumin (24-26) and FFA $(19,27)$ is claimed to be through biophysical interaction due to intrinsic surface activity. Enzymes in meconium inactivate surfactant by hydrolyzing its active agent dipalmitoylphosphatidylcholine (5) to lysophosphatidylcholine. Excessively, lysophosphatidylcholine inhibits surfactant (28).

We have recently shown that albumin attenuates pulmonary dysfunction in experimental MAS when it is mixed with meconium before instillation (29). This may be due to the high binding affinity of albumin for fatty acids and bilirubin (30). Additionally, the increase of IL- 8 in the animals instilled with 
pure meconium was 5 -fold compared with animals receiving albumin-meconium mixture (31). We wanted to test whether albumin could be beneficial to lung function and limit IL-8 increase in MAS by instilling it as rescue therapy after meconium.

\section{MATERIALS AND METHODS}

Animals. Thirty-six piglets (maximum $2 \mathrm{~d}$ old, Norwegian domestic race) were selected at two farms by two farmers and delivered on the day of experiments. Their weights were $1.8 \mathrm{~kg} \pm 0.08$. Exclusion criteria were as follows: 1$) \mathrm{Hb}<5 \mathrm{~g} / \mathrm{dL}, 2)$ oxygen saturation of $\mathrm{Hb}\left(\mathrm{SaO}_{2}\right)<90 \%$ before induction of hypoxia, and 3) death within $30 \mathrm{~min}$ of reoxygenation. Four animals were excluded in accordance with the death criterion, one because of low $\mathrm{Hb}$ and another due to surgical bleeding. As expected, some of the MAS animals died in the reoxygenation period beyond $30 \mathrm{~min}$, and mortality was highest in the groups receiving the highest dose of meconium (58\% in MAS I versus $36 \%$ in MAS II). No control animals died.

Anesthesia and surgery. Sleep was induced by 5\% halothane in an equal mixture of air and oxygen $(3+3 \mathrm{~L})$, and prolonged by $1-2 \%$ halothane. The piglets were tracheotomized in infiltration anesthesia (lidocaine, $10 \mathrm{mg} / \mathrm{mg}, 7$ $\mathrm{mg} / \mathrm{kg}$ maximum) and ventilated through an uncuffed endotracheal tube [inner diameter (ID), $3.5 \mathrm{~mm}$; Portex Ltd., Hythe, Kent, UK] by a ventilator (Babylog 8000 plus; Dräger Medical AG, Lübeck, Germany), shortly interrupted by manual ventilation (Laerdal silicone resuscitation bag, infant size; Laerdal, Stavanger, Norway) while sampling tracheal aspirates and for the first $30 \mathrm{~s}$ during the reoxygenation period. Halothane anesthesia was replaced by intravenous anesthesia, which was introduced by boluses of pentobarbital sodium $(20 \mathrm{mg} / \mathrm{kg})$, fentanyl $(50 \mu \mathrm{g} / \mathrm{kg})$, and pancuronium $(0.4 \mathrm{mg} / \mathrm{kg})$ and maintained by infusion of fentanyl $(50 \mu \mathrm{g} / \mathrm{kg} / \mathrm{h}, 25 \mu \mathrm{g} / \mathrm{kg} / \mathrm{h}$ during hypoxia), midazolam (250 $\mu \mathrm{g} / \mathrm{kg} / \mathrm{h}, 125 \mu \mathrm{g} / \mathrm{kg} / \mathrm{h}$ during hypoxia), and intermittent boluses of pancuronium $(0.01 \mathrm{mg} / \mathrm{kg})$. The infusions were given through polythene catheters (nonsterilized, Portex PE-50, ID $0.58 \mathrm{~mm}$, ID $0.96 \mathrm{~mm}$; Portex Ltd.) by syringe pumps (IVAC P 2000, Basingstoke, UK, and TERUMO STC-521, Tokyo, Japan) placed in the femoral vein. To monitor mean artery pressure (MAP) and central venous pressure (CVP), polythene catheters were also inserted in the femoral artery and jugular vein. To measure PAP and LAP, access to the pulmonary artery and left atrium was obtained through a left-sided thoracotomy. Cannulation was performed by Seldinger technique (Vygon leader catheter $20 \mathrm{G}-8 \mathrm{~cm}$; Vygon, Ecouen, France). By means of pressure transducers (Edwards Life Science, Hina Dominican Republic), hemodynamic data were collected in a computer system (Model MP 100; Biopac Systems Inc., Goleta, CA). Cardiac output (CO) was recorded with a flow probe (Cardio-Med Flow Probes, ID 7.5 mm; Medi-Stim Norge AS, Nydalen, Norway) enclosing the pulmonary artery.

Meconium. Meconium $(67.7 \mathrm{~g})$ was collected from 53 healthy human babies in $50 \mathrm{~mL}$ polypropylene centrifuge tubes (Corning Life Sciences, Corning, NY) and kept in $-20^{\circ} \mathrm{C}$ until received by the investigating team. This latency was only a matter of days, and the samples were then stored at $-20^{\circ} \mathrm{C}$. Only the first portion of stools was defined as meconium. The samples were then combined and processed by a hand blender (Bosch MSM 4001/01; Robert Bosch GmbH, Stuttgart, Germany) in normal saline until the mixture was homogenous. The batch was then freeze-dried and irradiated ( $\gamma$-rays, $32 \mathrm{kGy}$; Institute for Energy Technology, Kjeller, Norway). Finally, the preparation was reconstituted with saline to a weight concentration of $135 \mathrm{mg} / \mathrm{mL}$.

Experimental model. After surgery, hypoxia was induced by $8 \%$ oxygen in nitrogen (AGA, Oslo, Norway, ) and maintained until base excess was $\leq-20$ $\mathrm{mM}$. High doses of meconium were chosen to induce a disturbance in lung function comparative to that seen in infants requiring respiratory support. Meconium [MAS I: $675 \mathrm{mg} / \mathrm{kg}$ (dry weight), $n=12$; MAS II: $540 \mathrm{mg} / \mathrm{kg}, n$ $=14$ (both diluted in saline to a stock solution of $135 \mathrm{mg} / \mathrm{mL}$ )] was then instilled into the lungs and the piglets were randomized to receive either $30 \%$ bovine albumin $(1.4 \mathrm{~mL} / \mathrm{kg}=432 \mathrm{mg} / \mathrm{kg}$, essentially free of fatty acids, A-9205; Sigma Chemical Co., St. Louis, MO) or isotonic saline $(1.4 \mathrm{~mL} / \mathrm{kg}, 9$ $\mathrm{mg} / \mathrm{mL}$ ), both $5 \mathrm{~min}$ after meconium instillation. The albumin doses were calculated to achieve stoichiometric binding of FFA to albumin, and FFA concentration in meconium (dry weight) was measured to $10.7 \mathrm{nmol} / \mathrm{mg}$ by methods described previously (29). A control group $(n=4)$ was tested by sequential lung instillation of isotonic saline $(5 \mathrm{~mL} / \mathrm{kg})$ and albumin $(1.4$ $\mathrm{mL} / \mathrm{kg}$ ). After instillation of meconium/saline, the piglets were manually ventilated (Laerdal silicone resuscitation bag, infant size; Laerdal) 30 times in ambient air with the rate $1 / \mathrm{s}$ with an insufflation pressure (not measured with a manometer) securing visually adequate chest expansion. Subsequently, the piglets were coupled to the ventilator after increasing the settings: rate from 30 to $60 / \mathrm{min}$, the peak inspiratory pressure (PIP) $5 \mathrm{~cm} \mathrm{H}_{2} \mathrm{O}$ beyond the preceding
PIP and the fraction of inspired oxygen $\left(\mathrm{FiO}_{2}\right)$ from $8 \%$ to $21 \%$ for the first 10 $\mathrm{min}$ of the reoxygenation period. Later on, the ventilator settings were adjusted as needed to keep $\mathrm{SaO}_{2}>85 \%$ and $\mathrm{PCO}_{2}$ in the range of 4-6 kPa. Maximum ventilator settings were as follows: rate, 60/min; $\mathrm{FiO}_{2}, 90 \%$; and PIP, $45 \mathrm{~cm}$ $\mathrm{H}_{2} \mathrm{O}$.

The ventilator monitored lung function. Mean airway pressure was measured at the Y-piece and lung volumes calculated as a function of flow. Dynamic compliance $\left(\mathrm{C}_{\mathrm{dyn}}\right)$ and resistance $(\mathrm{R})$, and their product, the time constant $(\mathrm{Tc})$, were calculated with aid of a computer program (Drägerwerk AG, Lübeck, Germany) integrated in the ventilator. OI was calculated according to the following formula: $\mathrm{OI}=\left(\mathrm{MAP} \times \mathrm{FiO}_{2}\right) /\left(\mathrm{PaO}_{2} \times 7.5\right)$, where MAP $=$ mean airway pressure $(\mathrm{mbar})$ and $\mathrm{PaO}_{2}$ was measured in kilopascals. VI was calculated according to the following formula: $\mathrm{VI}=\left(\mathrm{PaCO}_{2} \times 7.5 \times \mathrm{F} \times\right.$ $\mathrm{PIP} / 1000$, where $\mathrm{PaCO}_{2}$ was measured in kilopascals, $\mathrm{F}=$ frequency of ventilation/minute, and PIP $=$ peak inspiratory pressure (mbar).

Sampling. Arterial blood gas tensions and base excess were determined on $0.2 \mathrm{~mL}$ samples withdrawn from the femoral artery and analyzed (CibaCorning blood gas analyzer 860; Bayer HealthCare Diagnostics Division, Tarrytown, NY). Samples were taken during surgery, at baseline, during hypoxia, at 10, 20,30, 60, and $90 \mathrm{~min}$ of reoxygenation, and then every hour until $8 \mathrm{~h}$ of reoxygenation. The catheter in the femoral artery was continuously flushed with heparin $(2 \mathrm{IU} / \mathrm{mL}) 3 \mathrm{~mL} / \mathrm{h}$. The $\mathrm{Hb}$ level was measured at the start and end of the experiment (Ciba-Corning 279 Co-oximeter; Bayer HealthCare Diagnostics Division). The total withdrawal of blood volume was $<10 \%$ of the total blood volume.

Tracheal aspirations (TA) were done on four occasions during every experiment, with great care to avoid the stress it might cause as far as lung function and blood pressure are concerned. After instillation of $2 \mathrm{~mL}$ saline in the trachea, aspiration was performed with a maximum suction pressure of 20 $\mathrm{kPa}$, followed by hand ventilation for $30 \mathrm{~s}$. After centrifugation (3000 rpm for $5 \mathrm{~min}$ ), supernatant was preserved in $-24^{\circ} \mathrm{C}$ and thawed for IL-8 (ELISA kit, swine; BioSource International, Camarillo, CA) and protein analyses (BCA protein assay kit; Pierce Biotechnology, Inc., Rockford, IL).

Statistics. To visualize the variability, the mean value for all continuous values are given with $95 \%$ confidence interval (CI). For intra- or intergroup comparisons of maximum two measurements, $95 \%$ CI was used. Delta values were used to correct for differences between animals at baseline, and start of hypoxia $\left(\mathrm{H}_{0}\right)$ was chosen as baseline. Due to lack of normal distribution, VI and OI were $\log$ transformed for testing of differences between the groups. ANOVA was used to compare groups whenever more than two measurements for each piglet were compared. Outcome (dependent) variables were lung compliance, OI, VI, PAP, CO, and LAP. Predictor (explanatory) variables were time, albumin versus saline, and meconium versus controls. Pearson correlation coefficients were estimated to model the linear relationship between variables. Bonferroni correction was chosen as posthoc test. Rejection probability in hypothesis testing was set to $5 \%$.

Ethics. The Norwegian Animal Experimental Board approved the experimental protocol.

\section{RESULTS}

Hemodynamics. CO decreased and PAP increased during hypoxia in MAS as well as in control animals (Table 1). After meconium instillation, PAP was significantly higher in MAS II animals $(540 \mathrm{mg} / \mathrm{kg})$ compared with control animals $(p<$ 0.005) (Table 1). There were no differences in LAP or CVP. No differences were observed comparing saline as rescue therapy versus albumin in any of the hemodynamic variables (data not shown).

Oxygenation and ventilation. In MAS animals with the highest meconium dose (MAS I $=675 \mathrm{mg} / \mathrm{kg}$ ), an increase was observed in OI from $1.4 \pm 0.1$ (baseline) to $12.8 \pm 1.8$ (mean $\pm \mathrm{CI}$ for all time points after instillation of meconium), with a maximum (25.4 \pm 3.4$)$ at $6 \mathrm{~h}$ (Fig. 1). In MAS animals with the lower meconium dose (MAS II $=540 \mathrm{mg} / \mathrm{kg}$ ), an increase was observed in OI from $1.4 \pm 0.1$ (baseline) to $7.3 \pm$ 1.2 (mean \pm CI for all time points after instillation of meconium), with a maximum $(12 \pm 2.8)$ at $5 \mathrm{~h}$ after instillation of meconium (Fig. 1). For the first 10 min of reoxygenation, OI increased equally in all groups, including controls $(p<0.001$, 
Table 1. Hemodynamic data in experimental MAS induced in newborn piglets at start of reoxygenation $\left(R_{O}\right)$ and observed for an additional $8 \mathrm{~h}$

\begin{tabular}{|c|c|c|c|c|c|c|c|c|c|c|c|}
\hline & $\mathrm{H}_{0}$ & $\mathrm{R}_{0}$ & $30 \mathrm{~min}$ & $1 \mathrm{~h}$ & $2 \mathrm{~h}$ & $3 \mathrm{~h}$ & $4 \mathrm{~h}$ & $5 \mathrm{~h}$ & $6 \mathrm{~h}$ & $7 \mathrm{~h}$ & $8 \mathrm{~h}$ \\
\hline \multicolumn{12}{|l|}{ CVP } \\
\hline Control & $4 \pm 1$ & $5 \pm 1$ & $5 \pm 1$ & $5 \pm 1$ & $5 \pm 1$ & $5 \pm 1$ & $5 \pm 1$ & $5 \pm 1$ & $6 \pm 1$ & $5 \pm 1$ & $5 \pm 1$ \\
\hline MAS I & $4 \pm 1$ & $5 \pm 1$ & $5 \pm 1$ & $5 \pm 1$ & $5 \pm 1$ & $5 \pm 1$ & $5 \pm 1$ & $5 \pm 1$ & $5 \pm 1$ & $5 \pm 1$ & $5 \pm 1$ \\
\hline \multicolumn{12}{|l|}{ LAP } \\
\hline Control & $5 \pm 2$ & $5 \pm 1$ & $6 \pm 1$ & $6 \pm 2$ & $5 \pm 1$ & $5 \pm 1$ & $6 \pm 1$ & $6 \pm 1$ & $6 \pm 2$ & $6 \pm 1$ & $6 \pm 1$ \\
\hline MAS I & $4 \pm 1$ & $5 \pm 1$ & $5 \pm 1$ & $5 \pm 1$ & $4 \pm 1$ & $5 \pm 1$ & $5 \pm 1$ & $5 \pm 1$ & $8 \pm 6$ & $6 \pm 1$ & $5 \pm 1$ \\
\hline Control & $21 \pm 2$ & $23 \pm 4$ & $31 \pm 5$ & $26 \pm 3$ & $25 \pm 3$ & $25 \pm 2$ & $24 \pm 4$ & $21 \pm 6$ & $24 \pm 4$ & $17 \pm 10$ & $19 \pm 22$ \\
\hline MAS I & $19 \pm 2$ & $33 \pm 4$ & $35 \pm 6$ & $29 \pm 4$ & $28 \pm 3$ & $26 \pm 5$ & $29 \pm 5$ & $26 \pm 6$ & $22 \pm 10$ & $30 \pm 10$ & $24 \pm 10$ \\
\hline MAS II & $22 \pm 2$ & $32 \pm 3$ & $34 \pm 3$ & $31 \pm 2$ & $32 \pm 1 *$ & $32 \pm 2 *$ & $35 \pm 4^{*}$ & $33 \pm 3^{*}$ & $36 \pm 4^{*}$ & $34 \pm 4^{*}$ & $32 \pm 10$ \\
\hline \multicolumn{12}{|l|}{$\mathrm{CO}$} \\
\hline Control & $351 \pm 69$ & $234 \pm 22$ & $383 \pm 199$ & $395 \pm 98$ & $363 \pm 72$ & $335 \pm 34$ & $346 \pm 30$ & $289 \pm 76$ & $273 \pm 22$ & $263 \pm 34$ & $324 \pm 34$ \\
\hline MAS I & $276 \pm 40$ & $231 \pm 40$ & $309 \pm 36$ & $298 \pm 32$ & $281 \pm 32$ & $273 \pm 34$ & $272 \pm 40$ & $245 \pm 36$ & $260 \pm 54$ & $294 \pm 60$ & $251 \pm 72$ \\
\hline
\end{tabular}

Experimental animals: meconium + saline/albumin [MAS I = $675 \mathrm{mg}$ dry weight human meconium $/ \mathrm{kg}$ piglet, $n=12$ (saline + albumin instilled); MAS II $=$ $540 \mathrm{mg} / \mathrm{kg}, n=14$ (saline + albumin instilled)]. Control animals: saline + albumin, $n=4 ; \mathrm{H}_{0}$, start of hypoxia; CVP, central venous pressure (mm Hg); CO, cardiac output (mL/min). Data are mean $\pm 95 \%$ CI.

$* p<0.05$, MAS $v s$ controls.
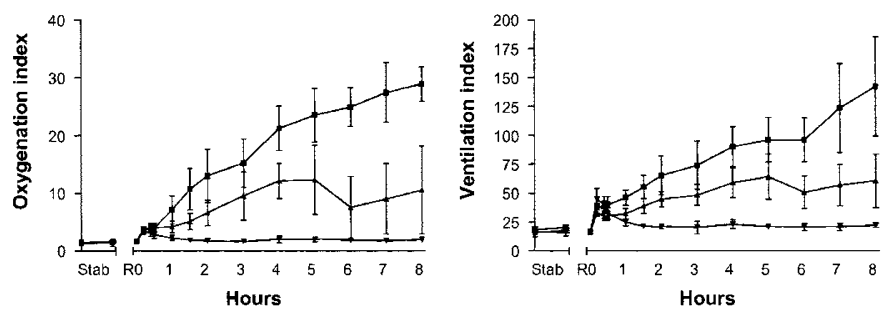

Figure 1. OI (left panel) and VI (right panel) in control animals (saline + albumin, $n=4)$ (inverted triangle) and experimental animals [meconium, 540 $\mathrm{mg} / \mathrm{kg}$ (MAS II) (triangle) + saline/albumin $(n=14)$; meconium, $675 \mathrm{mg} / \mathrm{kg}$ (MAS I) (square) + saline/albumin $(n=12)]$. $H$, hypoxia; Stab, period of stabilization before hypoxia; $R_{O}$, start of reoxygenation with instillation of meconium (MAS animals) or saline (controls). Data are mean $\pm 95 \%$ CI.

Fig. 1), but the courses separated after 30 min reoxygenation with a higher $(p<0.05)$ OI in all MAS animals after $60 \mathrm{~min}$. $\mathrm{PaO}_{2}$ tended correspondingly toward lower values in MAS animals versus controls (Table 2).

The development of VI was almost identical to OI in both MAS animals and control animals. In MAS I animals, an increase was observed in VI from $18.7 \pm 2.6$ (baseline) to 66.7 \pm 6.6 (mean \pm CI for all time points after instillation of meconium), with a maximum $(96 \pm 19.0)$ at $6 \mathrm{~h}$ after instillation of meconium (Fig. 1). In MAS II animals, an increase was observed in VI from $16.2 \pm 1.6$ (baseline) to $44.9 \pm 3.6$ (mean \pm CI for all time points after instillation of meconium), with a maximum $(64 \pm 19.4)$ at $5 \mathrm{~h}$ after instillation of meconium (Fig. 1). After $60 \mathrm{~min}$, VI was higher $(p<0.05)$ in MAS animals compared with control animals (Fig. 1). $\mathrm{PaCO}_{2}$ tended correspondingly toward higher values in MAS animals versus controls (Table 2).

No difference was observed comparing VI or OI in MAS animals receiving saline as rescue therapy versus albumin (VI, $p=0.36$; OI, $p=0.38$ ).

Compliance. Compliance (mL/mbar) was reduced $(46-$ $60 \%$ ) in all MAS animals and reached a minimum value at $4 \mathrm{~h}$ reoxygenation (Fig. 2). In the control animals, compliance decreased during hypoxia, but thereafter increased and almost reached baseline values during reoxygenation (Fig. 2). Compliance decreased more in MAS I piglets (meconium + saline: $-1.4 \pm 0.38$, meconium + albumin: $-1.2 \pm 0.52$ ) compared with MAS II (meconium + saline: $-1.0 \pm 0.38$, meconium + albumin: $-0.76 \pm 0.24$ ) (Fig. 2). Even though the differences were small, dynamic lung compliance was significantly higher if meconium instillation was followed by albumin instillation rather than saline instillation irrespective of dose of meconium (MAS I, $p=0.008$; MAS II, $p=0.002$ ). These differences, however, did not reach significance if changes from start of reoxygenation, $\mathrm{R}_{0}$ (data not shown), were calculated instead of changes from stabilization period following surgery.

$\boldsymbol{I L}$ - 8. IL-8 increased ( $p<0.001)$ in all MAS animals (Fig. 3). In MAS I animals (675 mg/kg), a 10-fold increase was observed from baseline $(1 \pm 0.4 \mu \mathrm{g} / \mathrm{mL})$ to maximum $(10 \pm 1.7 \mu \mathrm{g} / \mathrm{mL})$ at $4 \mathrm{~h}$ after instillation of meconium (Fig. 3). In MAS II animals $(540 \mathrm{mg} / \mathrm{kg})$, a 5 -fold increase was observed from baseline (2 \pm $0.7 \mu \mathrm{g} / \mathrm{mL})$ to maximum $(10 \pm 1.3 \mu \mathrm{g} / \mathrm{mL})($ Fig. 3$)$ at $8 \mathrm{~h}$ after instillation of meconium. By contrast, tracheal proteins increased only 112\% (MAS I) and 58\% (MASII) (Fig. 3), respectively. The increase in IL-8 correlated with deterioration of lung function [MAS I-OI: $r=0.71, p<0.0001$; VI: $r=0.71, p<0.0001$; compliance: $r=-0.66, p<0.0001$ (Fig. 4); and MAS II-OI: $r=0.49, p=0.0002$; VI: $r=0.66, p<0.0001$; compliance: $r$ $=-0.59, p<0.0001$ (Fig. 5)]. In the control animals, nonsignificant increases of IL-8 (18\%) and protein (16\%) were observed from baseline to culmination (Fig. 3). In the control animals, no correlations between IL-8 and lung function (OI, VI, and compliance) were observed (data not shown). Finally, we observed no difference in MAS animals receiving saline as rescue therapy versus albumin (data not shown).

\section{DISCUSSION}

We observed a significant increase of IL- 8 in piglet lungs after instillation of meconium. The IL- 8 increase correlated 
Table 2. Blood gas measurements from start of reoxygenation $\left(R_{O}\right)$ and for an additional $8 \mathrm{~h}$

\begin{tabular}{|c|c|c|c|c|c|c|}
\hline & $\mathrm{H}_{0}$ & $\mathrm{R}_{0}$ & $30 \mathrm{~min}$ & $1 \mathrm{~h}$ & $2 \mathrm{~h}$ & $3 \mathrm{~h}$ \\
\hline \multicolumn{7}{|l|}{$\mathrm{pH}$} \\
\hline Control & $7.47 \pm 0.06$ & $7.08 \pm 0.02$ & $7.25 \pm 0.06$ & $7.43 \pm 0.04$ & $7.42 \pm 0.02$ & $7.42 \pm 0.04$ \\
\hline MAS I & $7.46 \pm 0.02$ & $7.09 \pm 0.02$ & $7.09 \pm 0.04^{*}$ & $7.15 \pm 0.08^{*}$ & $7.21 \pm 0.06^{*}$ & $7.22 \pm 0.1^{*}$ \\
\hline \multicolumn{7}{|l|}{$\mathrm{PaO}_{2}$} \\
\hline Control & $9.4 \pm 0.6$ & $4.0 \pm 0.4$ & $9.1 \pm 1.2$ & $10.1 \pm 1.6$ & $9.8 \pm 1.4$ & $11.4 \pm 2.0$ \\
\hline MAS I & $10.9 \pm 0.8^{*}$ & $3.9 \pm 0.2$ & $6.7 \pm 0.8^{*}$ & $9.4 \pm 0.6$ & $8.6 \pm 0.8$ & $7.33 \pm 0.6^{*}$ \\
\hline Control & $3.9 \pm 0.6$ & $3.9 \pm 0.2$ & $3.3 \pm 0.4$ & $3.6 \pm 0.4$ & $4.4 \pm 0.3$ & $4.4 \pm 0.8$ \\
\hline MAS I & $4.4 \pm 0.3$ & $3.8 \pm 0.3$ & $4.4 \pm 0.6^{*}$ & $5.1 \pm 0.3^{*}$ & $5.8 \pm 0.6^{*}$ & $5.8 \pm 0.8$ \\
\hline MAS II & $4.0 \pm 0.3$ & $3.7 \pm 0.3$ & $3.6 \pm 0.2$ & $4.1 \pm 0.4$ & $4.8 \pm 0.2$ & $4.8 \pm 0.6$ \\
\hline
\end{tabular}

Continued

with a significant deterioration of lung function. Mortality and morbidity were related to the amount of meconium instilled. Dynamic lung compliance in piglets with MAS was higher if albumin was instilled as rescue therapy versus saline. In spite of the use of high doses of meconium, there was no evidence for an early obstructing phase in our experiment, which may be due to reduction of the particle size of this meconium below the point of producing obstruction.

It has been documented that the chemotactic activity of meconium on neutrophils may be caused by IL-8 (32) present in meconium (16). Our data indicate de novo synthesis of IL-8 in MAS animals, in accordance with an earlier study in our group on piglets (31) executed with lower doses of meconium $(330 \mathrm{mg} / \mathrm{kg}$ ). As opposed to the study of Tollofsrud et al. (31), we found a highly significant correlation between IL-8 and deterioration of oxygenation, ventilation, and compliance. However, we did not reproduce significant differences in IL-8 between albumin- and saline-treated MAS animals as shown by Tollofsrud et al. (31). Inasmuch as IL-8 is known to be produced in acute inflammation (33), the increase of IL-8 simultaneously to deterioration of lung function raises the possibility that meconium triggers lung inflammation within the first hours after instillation, and, further, this inflammation may cause reduction of oxygenation, ventilation, and compliance.
Because harvesting specific lung proteins, e.g. cytokines, by tracheal aspiration may be suboptimal as an estimate of the actual level of these proteins, we also analyzed for total protein content in tracheal aspirates. The increases of IL-8 exceeded that of total protein, which may be due to inflammation caused by meconium. Local production of IL-8 may cause lung damage through chemotaxis on neutrophile granulocytes.

IL-8 has been documented in cord blood of premature newborns (34) in levels clearly below what we measured in the lungs. Our results indicate local production in the lungs only and do not permit any conclusions regarding systemic level of IL-8. Nevertheless, it seems reasonable that levels of cytokines in the lung should exceed blood levels provided lung inflammation.

Lung inflammation and local IL-8 production might be due to volu- and barotraumas (35). The insufflation pressures in the animals aspirated with meconium had to be much higher to achieve the same tidal volume as control animals. On the other hand, it may be tidal volume rather than insufflation pressure that is of concern $(36,37)$. In fact, in comparing meconium animals to controls, our tidal volumes were not different, and, therefore, our data may indicate IL- 8 production in the lungs due to inflammation caused by meconium.

The main determinants of dynamic lung compliance are surfactant and the elastic components of lung tissue (38).
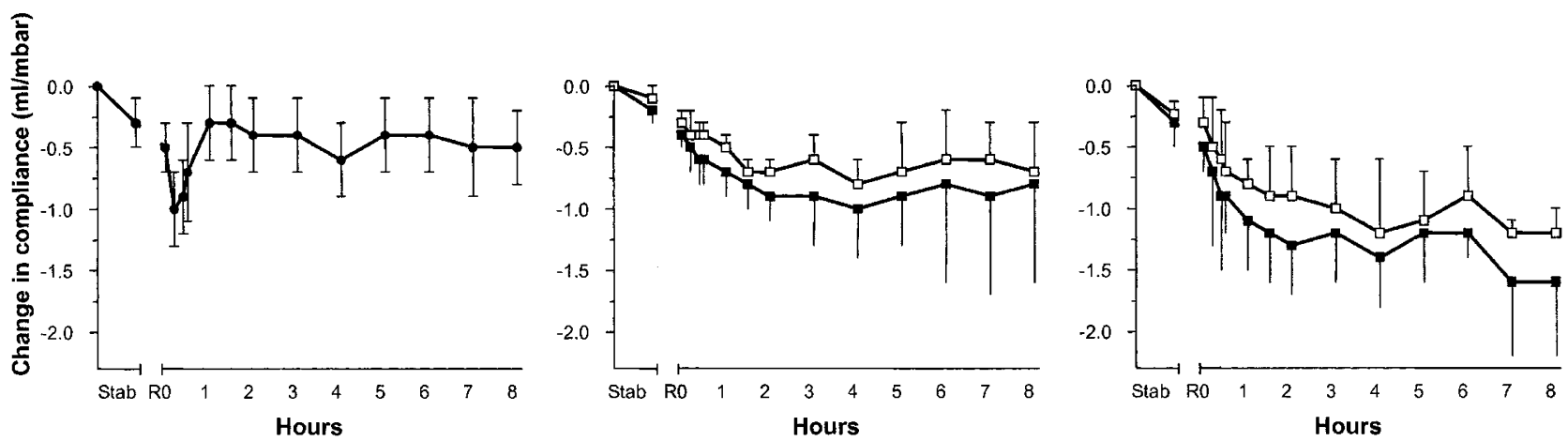

Figure 2. Effect of lung instillation of albumin $v s$ saline on lung compliance in experimental MAS. Left panel: control animal $(n=4)$ lung instilled with saline $(45 \mathrm{mg} / \mathrm{kg}$ piglet) and albumin $(1.4 \mathrm{~mL} / \mathrm{kg}, 30 \%)$. Middle panel: meconium dose: $540 \mathrm{mg} / \mathrm{kg}$ piglet (MAS II) [meconium + saline (filled square), $n=6$; meconium + albumin (open square), $n=8$ ]. Right panel: meconium dose: $675 \mathrm{mg} / \mathrm{kg}$ piglet (MAS I) [meconium + saline (filled square), $n=6$ and meconium + albumin (open square), $n=6$ ] Stab, period of stabilization before hypoxia; $R_{0}$, start of reoxygenation with instillation of meconium (MAS animals) or saline (controls). Data are mean $\pm 95 \%$ CI. 
Table 2. Blood gas measurements from start of reoxygenation $\left(R_{O}\right)$ and for an additional $8 \mathrm{~h}$

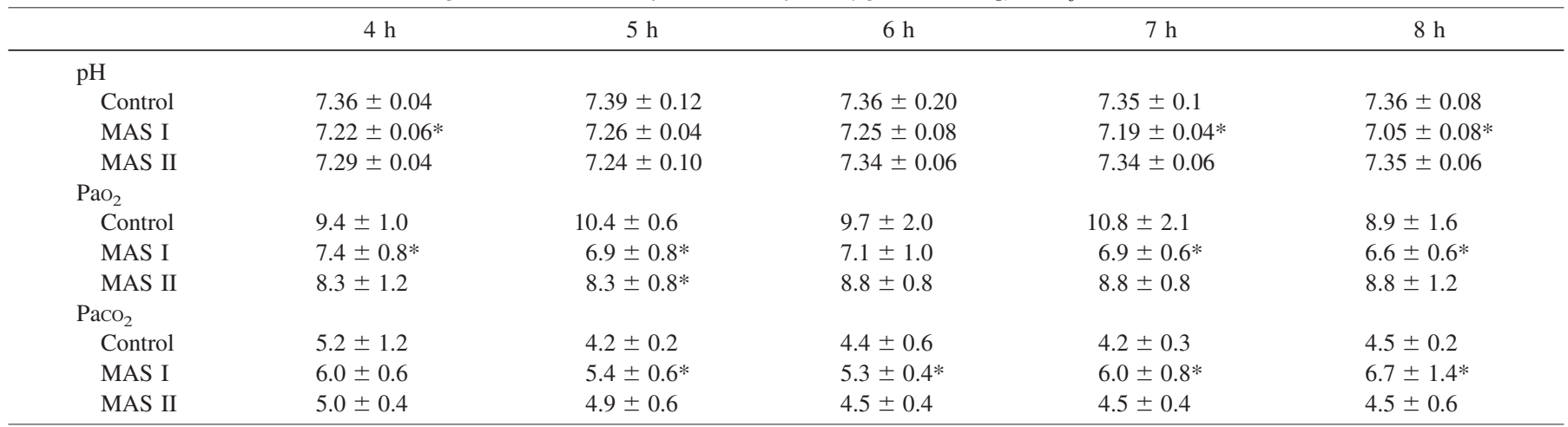

MAS I, $675 \mathrm{mg}$ dry weight meconium $/ \mathrm{kg}$ piglet, $n=12$ (saline + albumin instilled); MAS II $=540 \mathrm{mg} / \mathrm{kg}, n=14$ (saline + albumin instilled). Control animals $(n=4)$ received saline + albumin. Data are mean $\pm 95 \%$ CI.

$* p<0.05$, MAS vs controls.

Several in vitro studies indicate that both albumin $(24-26$, $39-42)$ and meconium $(4-6,23,43)$ inhibit surfactant, so one might expect an additive inhibition of surfactant when combining albumin and meconium in vivo. Provided a lack of influence on the elastic components, surfactant inhibition should reduce compliance. On the contrary, we found an increase rather than reduction in dynamic lung compliance in the piglets receiving both meconium and albumin compared with those receiving meconium and saline. Our findings are in agreement with previous in vivo studies from our group show-

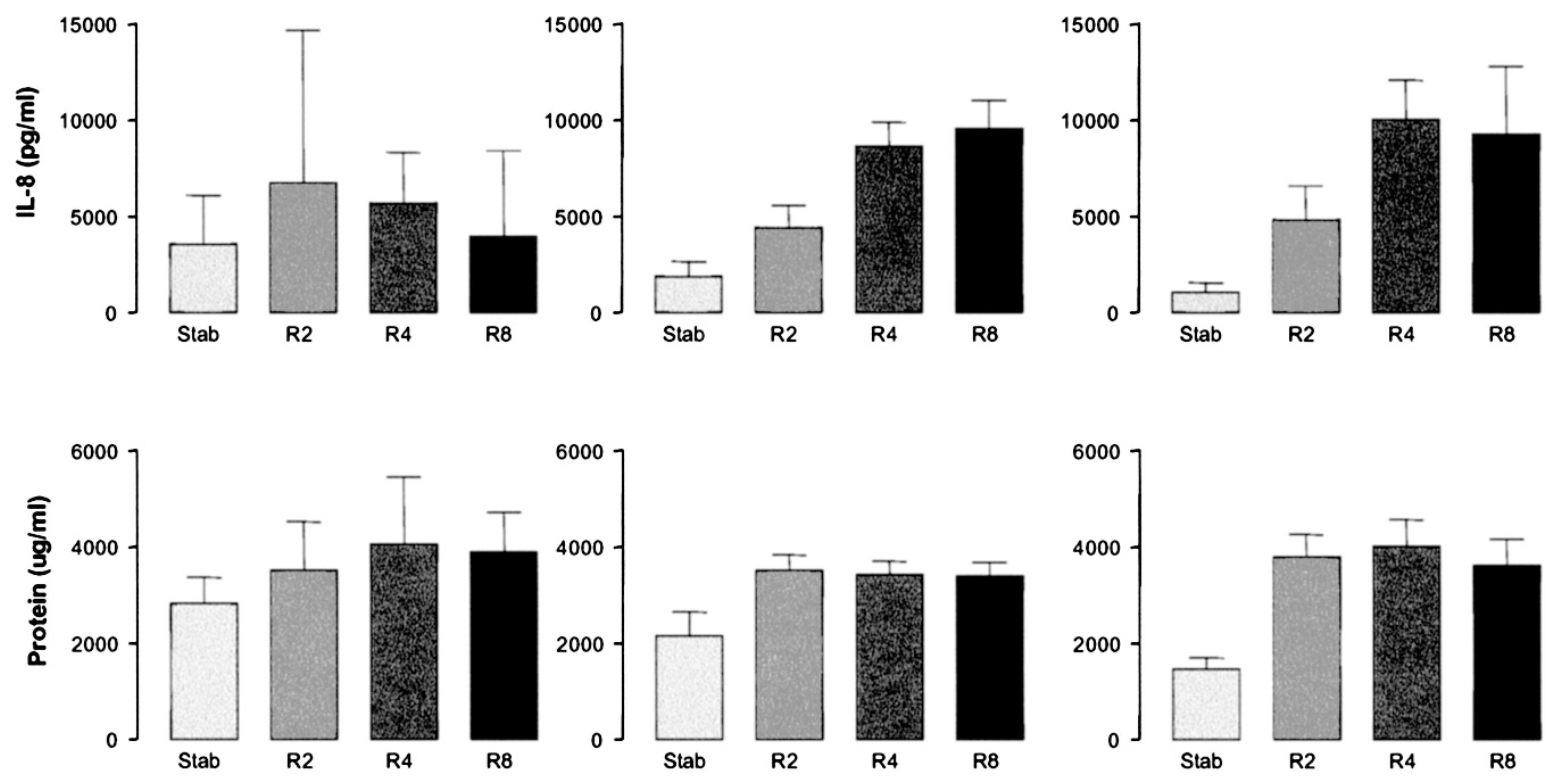

Figure 3. Tracheal IL-8 (upper panels) and tracheal protein (lower panels) for control $(n=4)$ (left panels), MAS II (middle panels), and MAS I animals (right panels). Stab, period of stabilization before hypoxia; $R_{2-8}$, hours of reoxygenation. Data are mean $\pm 95 \%$ CI.

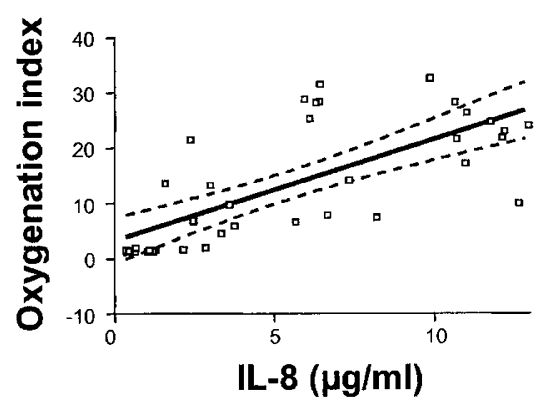

$\mathrm{r}=0.71, \mathrm{p}<0.0001$
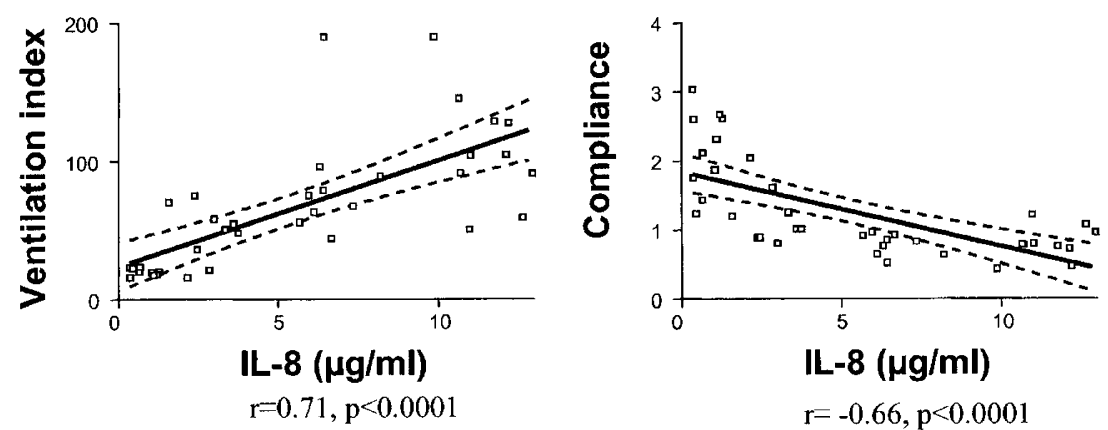

Figure 4. Correlation between IL-8 and OI (upper panel), IL-8 and VI (middle panel), and IL-8 and lung compliance (lower panel) after lung instillation of meconium, $675 \mathrm{mg} / \mathrm{kg}$ (MAS I). 


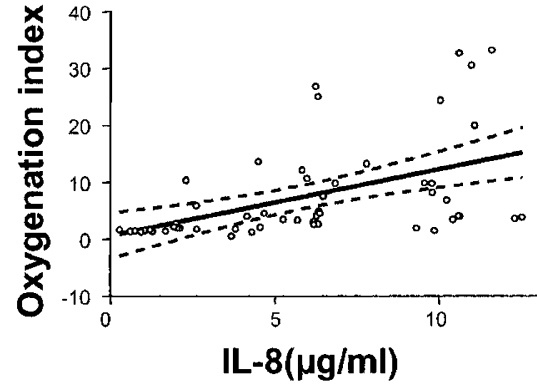

$\mathrm{r}=0.49, \mathrm{p}=0.0002$
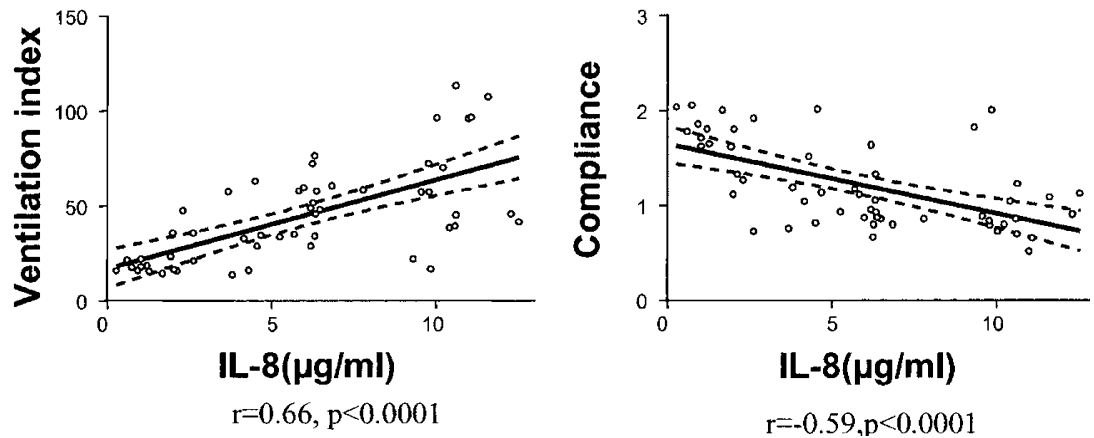

Figure 5. Correlation between IL-8 and OI (upper panel), IL-8 and VI (middle panel), IL-8 and lung compliance (lower panel) after lung instillation of meconium, $540 \mathrm{mg} / \mathrm{kg}$ (MAS II).

ing that adding albumin to meconium before instilling it as an intratracheal bolus reduces pulmonary insufficiency (29).

Albumin may inactivate surfactant inhibitors in meconium by binding them $(26,29)$, and further it is conceivable that an interaction between albumin and other surfactant inhibitors in meconium abolishes the potential inhibition of albumin, as well. In fact, this has been shown in vitro by combining albumin with arachidonic acid, palmitoleic acid, and oleic acid (26), all major FFA in meconium binding to albumin. In the same study, an additive inhibition was shown when combining albumin with phospholipids, which do not bind to albumin. This provides encouragement to the view that the effect of albumin on compliance could be independent of the way FFA in meconium might inhibit surfactant. We may speculate that albumin could influence other determinants of dynamic compliance like the elastic components, by for instance reducing edema through osmotic mechanisms or by a mucokinetic effect (44) on meconium by reducing its viscosity. Lung compliance could thereby be improved by increasing clearance of meconium from the airways.

We have not reproduced such lowering of OI, VI, and IL-8 in the albumin groups compared with the previous studies of Tollofsrud et al. $(29,31)$. However, there were major differences in the experimental protocols. The experiments share in common the stoichiometric relationship between measured FFA in the meconium pool and albumin instilled, but the effective dose of albumin in our study must be expected to be lower inasmuch as it was instilled sequentially to meconium and not simultaneously. Further, our study was with high doses of meconium, motivated by a wish to induce a disturbance in lung function comparative to that seen in infants requiring respiratory support. In fact, we used 97\% (MAS I $=675$ $\mathrm{mg} / \mathrm{kg}$ ) and $58 \%$ (MAS II $=540 \mathrm{mg} / \mathrm{kg}$ ) higher doses of meconium, respectively. Retrospectively, a higher albumin dose and volume should have been used, considering the enormous surface area of the lung and possible accumulation of albumin proximal to meconium in the lungs.

Several in vitro studies on surfactant inactivation have demonstrated the importance of the relative surfactant concentration to inhibitor concentrations $(6,22,23)$. This balance could in our experiments have been displaced compared with those seen in the study of Tollofsrud et al. (29). Moreover, our high-dose model leads to more serious detrimental effect on the lungs and may trigger systemic pathophysiological mechanisms like sys- temic inflammatory response syndrome. Serum protein leakage (42) to alveoli may be one aspect in a systemic disease and has been shown to exist already $1 \mathrm{~h}$ after meconium instillation in doses analogous to the study of Tollofsrud et al. (29). It has been proposed that plasma proteins leaking into the alveolus during lung edema and hemorrhage inhibit surfactant activity by biophysical mechanisms (41).

In conclusion, we have shown higher lung compliance in MAS by adding albumin after instillation of meconium. This may be due to inhibition of surfactant inhibitors in meconium by albumin, an effect possibly exceeding the surfactant inhibition of albumin. Further, we saw no early obstructing phase, but rather a rapid deterioration $2-3 \mathrm{~h}$ after instillation of meconium in the animals that seemed to be triggered to serious illness or death. A significant increase in lung IL-8 was observed simultaneously to deterioration of lung function in MAS animals. The mechanisms causing this phase must be further investigated.

Acknowledgments. The authors thank Roger Odegaard for highly skilled assistance in surgery, and Hilde Nilsen and Anne Randi Alvestad for excellent laboratory assistance.

\section{REFERENCES}

1. Tyler DC, Murphy J, Cheney FW 1978 Mechanical and chemical damage to lung tissue caused by meconium aspiration. Pediatrics 62:454-459

2. Tran N, Lowe C, Sivieri EM, Shaffer TH 1980 Sequential effects of acute meconium obstruction on pulmonary function. Pediatr Res 14:34-38

3. Terasaka D, Clark DA, Singh BN, Rokahr J 1986 Free fatty acids of human meconium. Biol Neonate 50:16-20

4. Clark DA, Nieman GF, Thompson JE, Paskanik AM, Rokhar JE, Bredenberg CE 1987 Surfactant displacement by meconium free fatty acids: an alternative explanation for atelectasis in meconium aspiration syndrome. J Pediatr 110:765-770

5. Schrama AJ, de Beaufort AJ, Sukul YR, Jansen SM, Poorthuis BJ, Berger HM 2001 Phospholipase A2 is present in meconium and inhibits the activity of pulmonary surfactant: an in vitro study. Acta Paediatr 90:412-416

6. Moses D, Holm BA, Spitale P, Liu MY, Enhorning G 1991 Inhibition of pulmonary surfactant function by meconium. Am J Obstet Gynecol 164:477-481

7. Fuchimukai T, Fujiwara T, Takahashi A, Enhorning G 1987 Artificial pulmonary surfactant inhibited by proteins. J Appl Physiol 62:429-437

8. Wu JM, Yeh TF, Wang JY, Wang JN, Lin YJ, Hsieh WS, Lin CH 1999 The role of pulmonary inflammation in the development of pulmonary hypertension in newborn with meconium aspiration syndrome (MAS). Pediatr Pulmonol Suppl 18:205-208

9. Holopainen R, Soukka H, Halkola L, Kaapa P 1998 Meconium aspiration induces a concentration-dependent pulmonary hypertensive response in newborn piglets. Pediatr Pulmonol 25:107-113

10. Cleary GM, Wiswell TE 1998 Meconium-stained amniotic fluid and the meconium aspiration syndrome. An update. Pediatr Clin North Am 45:511-529

11. Soukka H, Rautanen M, Halkola L, Kero P, Kaapa P 1997 Meconium aspiration induces ARDS-like pulmonary response in lungs of ten-week-old pigs. Pediatr Pulmonol 23:205-211 
12. Oelberg DG, Downey SA, Flynn MM 1990 Bile salt-induced intracellular $\mathrm{Ca}++$ accumulation in type II pneumocytes. Lung 168:297-308

13. Julien M, Hoeffel JM, Flick MR 1986 Oleic acid lung injury in sheep. J Appl Physiol 60:433-440

14. Wiswell TE, Gannon CM, Jacob J, Goldsmith L, Szyld E, Weiss K, Schutzman D, Cleary GM, Filipov P, Kurlat I, Caballero CL, Abassi S, Sprague D, Oltorf C, Padula M 2000 Delivery room management of the apparently vigorous meconium-stained neonate: results of the multicenter, international collaborative trial. Pediatrics 105:1-7

15. Wiswell TE 1992 Meconium aspiration syndrome made murkier. Am J Obstet Gynecol 167:1914-1916

16. de Beaufort AJ, Pelikan DM, Elferink JG, Berger HM 1998 Effect of interleukin 8 in meconium on in-vitro neutrophil chemotaxis. Lancet 352:102-105

17. Clark P, Duff P 1995 Inhibition of neutrophil oxidative burst and phagocytosis by meconium. Am J Obstet Gynecol 173:1301-1305

18. Soukka HR, Ahotupa M, Ruutu M, Kaapa PO 2002 Meconium stimulates neutrophil oxidative burst. Am J Perinatol 19:279-284

19. Lally KP, Mehall JR, Xue H, Thompson J 1999 Meconium stimulates a proinflammatory response in peritoneal macrophages: implications for meconium peritonitis. J Pediatr Surg 34:214-217

20. Li YH, Yan ZQ, Brauner A, Tullus K 2001 Meconium induces expression of inducible NO synthase and activation of NF-kappaB in rat alveolar macrophages. Pediatr Res 49:820-825

21. Kojima T, Hattori K, Fujiwara T, Sasai-Takedatsu M, Kobayashi Y 1994 Meconiuminduced lung injury mediated by activation of alveolar macrophages. Life Sci 54:1559-1562

22. Hall SB, Lu RZ, Venkitaraman AR, Hyde RW, Notter RH 1992 Inhibition of pulmonary surfactant by oleic acid: mechanisms and characteristics. J Appl Physiol $72: 1708-1716$

23. Kearney MS 1999 Chronic intrauterine meconium aspiration causes fetal lung infarcts, lung rupture, and meconium embolism. Pediatr Dev Pathol 2:544-551

24. Colacicco G, Basu MK 1978 Effect of serum albumin on dynamic force-area curve of dipalmitoyl lecithin. Respir Physiol 32:265-279

25. Holm BA, Notter RH, Finkelstein JN 1985 Surface property changes from interactions of albumin with natural lung surfactant and extracted lung lipids. Chem Phys Lipids 38:287-298

26. Wang Z, Notter RH 1998 Additivity of protein and nonprotein inhibitors of lung surfactant activity. Am J Respir Crit Care Med 158:28-35

27. Katz VL, Bowes WA Jr 1992 Meconium aspiration syndrome: reflections on a murky subject. Am J Obstet Gynecol 166:171-183

28. Grossmann G, Tashiro K, Kobayashi T, Suzuki Y, Matsumoto Y, Waseda Y, Akino T, Curstedt T, Robertson B 1999 Experimental neonatal respiratory failure induced by lysophosphatidylcholine: effect of surfactant treatment. J Appl Physiol 86:633-640
29. Tollofsrud PA, Medbo S, Solas AB, Drevon CA, Saugstad OD 2002 Albumin mixed with meconium attenuates pulmonary dysfunction in a newborn piglet model with meconium aspiration. Pediatr Res 52:545-553

30. Clark RH, Gerstmann DR, Jobe AH, Moffitt ST, Slutsky AS, Yoder BA 2001 Lung injury in neonates: causes, strategies for prevention, and long-term consequences. J Pediatr 139:478-486

31. Tollofsrud PA, Medbo S, Solas AB, Robertson B, Speer C, Seidenspinner S, Drevon CA, Saugstad OD 2004 Intratracheal albumin reduces IL-8 in tracheobronchial aspirates in piglets after meconium aspiration. J Perinat Med 32:81-86

32. Yamada T, Minakami H, Matsubara S, Yatsuda T, Kohmura Y, Sato I 2000 Meconium-stained amniotic fluid exhibits chemotactic activity for polymorphonuclear leukocytes in vitro. J Reprod Immunol 46:21-30

33. de Boer JP, Wolbink GJ, Thijs LG, Baars JW, Wagstaff J, Hack CE 1992 Interplay of complement and cytokines in the pathogenesis of septic shock. Immunopharmacology 24:135-148

34. Krueger M, Nauck MS, Sang S, Hentschel R, Wieland H, Berner R 2001 Cord blood levels of interleukin-6 and interleukin- 8 for the immediate diagnosis of early-onset infection in premature infants. Biol Neonate 80:118-123

35. Ranieri VM, Suter PM, Tortorella C, De Tullio R, Dayer JM, Brienza A, Bruno F, Slutsky AS 1999 Effect of mechanical ventilation on inflammatory mediators in patients with acute respiratory distress syndrome: a randomized controlled trial. JAMA 282:54-61

36. Pugin J, Dunn I, Jolliet P, Tassaux D, Magnenat JL, Nicod LP, Chevrolet JC 1998 Activation of human macrophages by mechanical ventilation in vitro. Am J Physiol 275:L1040-L1050

37. Chiumello D, Pristine G, Slutsky AS 1999 Mechanical ventilation affects local and systemic cytokines in an animal model of acute respiratory distress syndrome. Am J Respir Crit Care Med 160:109-116

38. West JB 1990 Mechanics of breathing. In: West JB (ed) Best and Taylor's Physiological Basis of Medical Practice, 12th Ed. Lippincott Williams \& Wilkins, Baltimore, pp 560-578

39. Ikegami M, Jobe A, Jacobs H, Lam R 1984 A protein from airways of premature lambs that inhibits surfactant function. J Appl Physiol 57:1134-1142

40. Holm BA, Notter RH 1987 Effects of hemoglobin and cell membrane lipids on pulmonary surfactant activity. J Appl Physiol 63:1434-1442

41. Holm BA, Enhorning G, Notter RH 1988 A biophysical mechanism by which plasma proteins inhibit lung surfactant activity. Chem Phys Lipids 49:49-55

42. Seeger W, Stohr G, Wolf HR, Neuhof H 1985 Alteration of surfactant function due to protein leakage: special interaction with fibrin monomer. J Appl Physiol 58:326-338

43. Sun B, Curstedt T, Robertson B 1993 Surfactant inhibition in experimental meconium aspiration. Acta Paediatr 82:182-189

44. Rubin BK, Tomkiewicz RP, Patrinos ME, Easa D 1996 The surface and transport properties of meconium and reconstituted meconium solutions. Pediatr Res 40:834-838 